\title{
RISCOS AMBIENTAIS ASSOCIADOS À OCUPAÇÃO ANTRÓPICA NO ENTORNO DE UMA UNIDADE DE CONSERVAÇÃO
}

Elizete Aparecida Checon de Freitas Lima ${ }^{1}$

Carolina Buso Dornfeld ${ }^{2}$

RESUMO

O presente trabalho apresenta uma análise do entorno de uma Unidade de Conservação, localizada na Região Noroeste do Estado de São Paulo: a Reserva Particular do Patrimônio Natural Foz do Rio Aguapeí. Por meio da análise da ocupação antrópica do seu entorno, foram indicados potenciais riscos ambientais para a reserva, fornecendo elementos para subsidiar a tomada de decisão sobre a gestão territorial do entorno dessa unidade de conservação.

PALAVRAS-CHAVE: Unidade de Conservação. Reserva. Riscos ambientais.

\section{ENVIRONMENTAL RISKS ASSOCIATED WITH HUMAN OCCUPATION IN THE VICINITY OF A CONSERVATION UNIT}

\begin{abstract}
This paper presents an analysis of the environment of a conservation area, located in the Northwestern Region of the State of São Paulo: the Reserva particular do Patrimônio Natural Foz do Rio Aguapeí. Through analysis of the human occupation of your surroundings, potential environmental risks to the reserve were shown, providing evidence to support decision-making on land management surrounding this conservation unit.
\end{abstract}

KEY-WORDS: Conservation Unit. Reserve. Environmental risks.

\footnotetext{
${ }^{1}$ Doutorado em Ecologia, Docente da UNESP, Campus de llha Solteira.eacflima@bio.feis.unesp.br.

${ }^{2}$ Doutorado em Ciências da Engenharia Ambiental, Docente da UNESP, Campus de llha Solteira, carolina@bio.feis.unesp.br.
} 


\section{OS RIESGOS AMBIENTALES ASOCIADOS A LA OCUPACIÓN HUMANA EN LAS PROXIMIDADES DE UN ÁREA PROTEGIDA}

\section{RESUMEN}

Este artículo presenta un análisis del entorno de un área de conservación, ubicada en la Región Noroeste de São Paulo: la Reserva Privada de Patrimonio Natural Foz do Rio Aguapeí. Mediante del análisis de la ocupación humana de su entorno, se muestran los posibles riesgos ambientales para la reserva, proporcionando evidencia para apoyar la toma de decisiones en la gestión de la tierra que rodea a esta unidad de conservación.

PALABRAS-CLAVE Unidades de Conservación. Reserva. Riesgos ambientales.

\section{INTRODUÇÃO}

A proteção legal de áreas naturais figura como um dos principais instrumentos, para conter a perda de áreas naturais (PRIMACK \& RODRIGUES, 2001) que tende a acompanhar o modelo atual de desenvolvimento econômico. Estabelecer áreas protegidas, entretanto, não garante a efetividade da conservação da biodiversidade nessas áreas. Fatores de várias ordens concorrem para limitar a eficácia de tal instrumento, tais como a adequação da definição sob qual área proteger, a categoria de conservação mais recomendada, a interação com outras áreas naturais, a situação fundiária da área protegida e sua relação com o entorno.

As áreas protegidas consistem, na maioria das vezes, em manchas isoladas de remanescentes naturais, imersas em uma matriz de paisagem antrópica. Essa situação compromete muito a função das áreas protegidas de manutenção da integridade de habitats e conservação das espécies.

A conectividade entre áreas naturais, por meio de corredores ecológicos, busca minimizar a fragmentação de habitas e seus efeitos ecológicos resultantes. Entretanto, nem sempre é viável a conexão direta entre as áreas naturais. Nesse caso, o aumento da permeabilidade da paisagem por meio de um uso do solo mais 
favorável ao fluxo gênico, se apresenta como uma alternativa para a conservação das espécies na região.

Muitos aspectos estão envolvidos na complexa interação existente entre a área protegida e seu entorno, sendo a conectividade entre habitats apenas um deles. O entorno de uma área protegida pode ser ocupado por assentamentos rurais, pequenas, médias e grandes propriedades agrícolas, cidades, empreendimentos minerários, industriais, dentre muitos outros tipos de usos do solo. Cada um desses usos acarreta riscos ambientais específicos à área protegida.

O entendimento de que, a área de entorno de uma área protegida deva constituir-se em uma zona de amortecimento de impactos advindos de seu entorno, está presente na lei que criou o Sistema Nacional de Unidades de Conservação (SNUC) (BRASIL, 2000). A compreensão da zona de amortecimento como uma área que deve receber atenção maior, com possibilidades de limitação a determinadas atividades antrópicas, também está presente na Resolução 428 do CONAMA (Conselho Nacional de Meio Ambiente), de 17 de dezembro de 2010, a qual dispõe sobre o licenciamento de empreendimentos de significativo impacto ambiental que possam afetar uma unidade de conservação ou sua zona de amortecimento (BRASIL, 2010). A eficácia desses instrumentos jurídicos, entretanto, ainda é objeto de discussão (VITALLI et al, 2009).

Os mecanismos legais que pretendem limitar a implantação de atividades antrópicas que causem impactos significativos nas Unidades de Conservação ou, no seu entorno, não dão conta da diversidade de situações de ocupação antrópica dessa região. As terras situadas ao redor das unidades de conservação são, na maioria dos casos, de propriedade particular, um fator complicador à gestão territorial do entorno de uma área protegida.

Em muitas situações, as pressões vindas das populações do entorno das unidades de conservação representam obstáculos na garantia da integridade da biodiversidade presente nesses locais (TORRES et al, 2009).

O presente trabalho apresenta uma análise do entorno de uma Unidade de Conservação, localizada na Região Noroeste do Estado de São Paulo: a Reserva Particular do Patrimônio Natural Foz do Rio Aguapeí. Essa é uma das regiões do 
estado com menor cobertura de vegetação nativa e de unidades de conservação. Por meio da análise da ocupação antrópica do seu entorno, pretende-se indicar os potenciais riscos ambientais para a reserva, fornecendo elementos para a tomada de decisão sobre a gestão territorial do entorno dessa unidade de conservação.

\section{ÁREA DE ESTUDO}

A área de estudo do presente trabalho foi o Reassentamento Rural Fazenda Buritis, localizado no Município de Paulicéia, SP, no entorno da Reserva Particular do Patrimônio Natural (RPPN) Foz do Rio Aguapeí. Essa reserva, de propriedade da CESP (Companhia Energética de São Paulo) foi criada em 2010 (Resolução SMA 117/2010), constituindo-se uma das poucas unidades de conservação existentes na Região Noroeste do Estado de São Paulo, abrangendo terras dos municípios de Castilho, São João do Pau D' Alho e Paulicéia (Figura 1). Apresenta uma grande diversidade de ambientes e de espécies de ecossistemas úmidos, estando conectada com o Parque Estadual do Aguapeí. A RPPN e o Parque formam um conjunto de 23 mil hectares, conhecido como Pantanal Paulista (APOENA, 2011). O reassentamento (Figura 2) foi implantado pela CESP (Companhia Energética de São Paulo), como forma de compensação pelos impactos causados na área de influência da construção das Usinas Hidrelétricas de Porto Primavera e Jupiá. 
Figura 1 - Localização da RPPN Foz do Rio Aguapeí (A), na Região Noroeste do Estado de São Paulo (B), englobando áreas dos municípios de Castilho, São João do Pau D’Alho e Paulicéia.

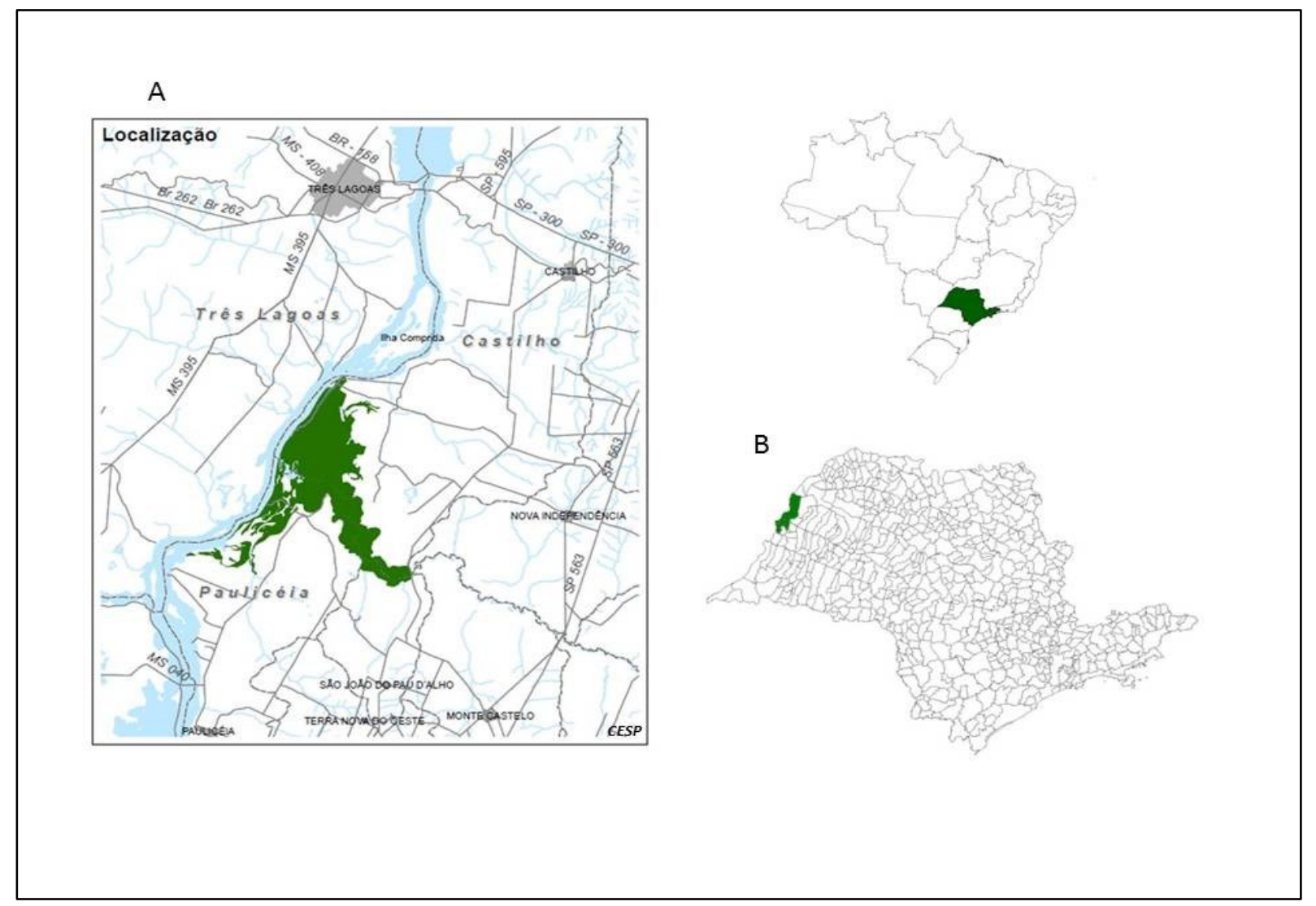

Fonte: www.cesp.com.br. Org. Hélio Ricardo Silva (UNESP, Ilha Solteira). 2014. 
Figura 2 - Vista em detalhe do Reassentamento Rural Fazenda Buritis, localizado próximo à RPPN Foz do Rio Aguapeí. No centro do reassentamento, observa-se um fragmento florestal, constituindo sua Reserva Legal.

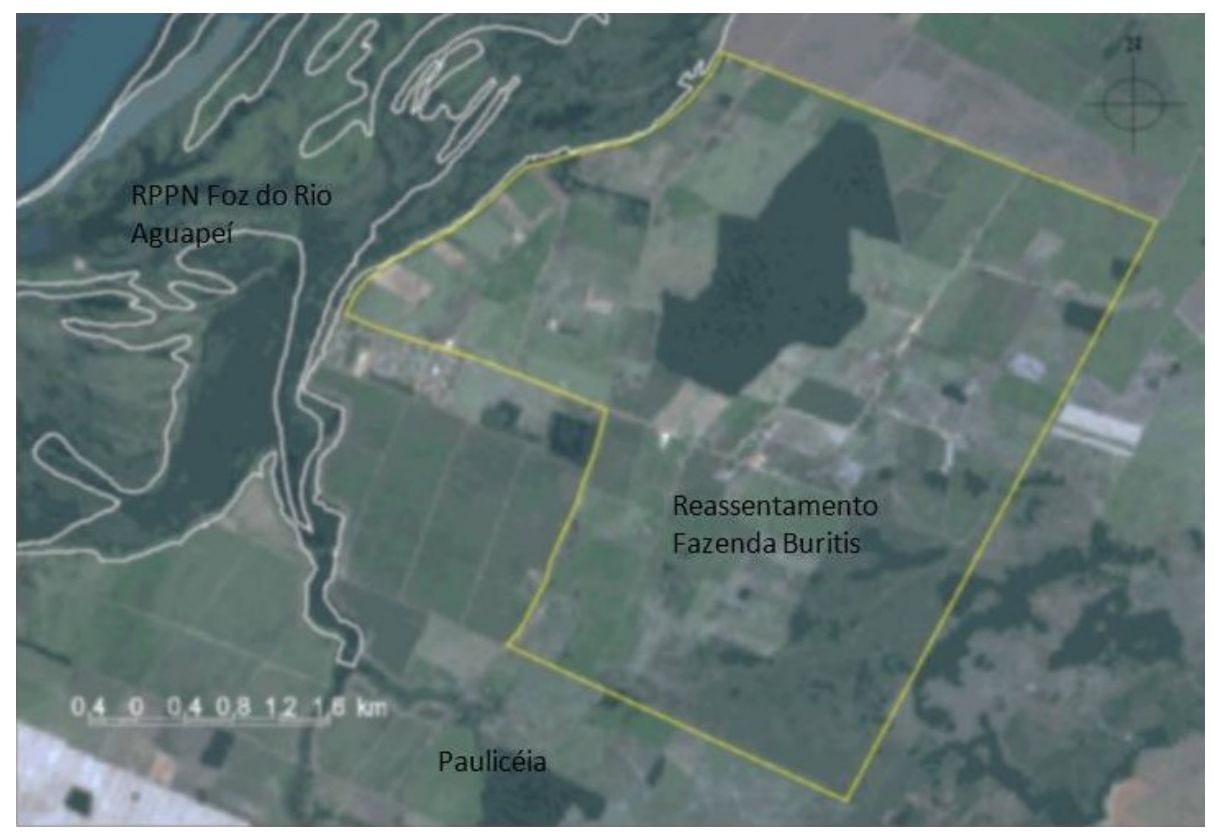

Fonte: Imagem Landsat 8, de 11/05/2014 (órbita/ponto 223/75). Escala 1:20000.

Org. Hélio Ricardo Silva (UNESP, Ilha Solteira). 2014.

\section{PROCEDIMENTOS METODOLÓGICOS}

A pesquisa de campo foi realizada no ano de 2012, combinando a observação direta com a aplicação de um questionário, durante as visitas realizadas nas unidades habitacionais do reassentamento.

O termo risco ambiental foi utilizado no presente estudo como uma "possibilidade de degradação do componente (desestruturação, contaminação), sendo qualitativo e na maioria das vezes adimensional em termos de ocorrência e magnitude de impacto", seguindo o conceito adotado por Bordest (1992), Pires (1995) e Freitas Lima (2007).

\section{RESULTADOS E DISCUSSÃO}


No reassentamento foram entrevistados moradores de 43 famílias, incluindo a quase totalidade das famílias que residiam no reassentamento. Os entrevistados tinham média de idade de 47 anos e maioria dos membros das famílias entrevistadas era composta por adultos. A maioria dos lotes do reassentamento apresentava produção agrícola, própria ou por meio de arrendamento para plantio de cana. Foi encontrado também um lote em que havia a presença de uma olaria.

A metade dos entrevistados relatou o uso de agrotóxicos em suas propriedades. Além do risco ambiental de contaminação ambiental, associado à aplicação desses produtos, também existe aquele relativo ao descarte inadequado de suas embalagens. A queima das embalagens foi a principal forma de destinação desse tipo de resíduo sólido.

A queima foi também a principal forma de destinação do lixo doméstico, de acordo com os entrevistados. Importante destacar que no reassentamento não foi relatada a existência de serviço público de coleta de lixo doméstico e apenas $21 \%$ dos entrevistados afirmaram realizar alguma forma de reciclagem do lixo doméstico, mediante atitude própria.

A queima é uma das ações antrópicas, realizadas no reassentamento, que mais pode implicar em riscos ambientais para a RPPN Foz do Rio Aguapeí. Os entrevistados citaram a queima do lixo, bem como a inexistência de um local adequado para sua disposição como alguns dos problemas ambientais do reassentamento. Outros problemas citados incluíram as queimadas que ocorrem nas matas e nas plantações de cana, a derrubada de árvores e uso de agrotóxicos, realizada pelas usinas de açúcar e álcool, a monotonia da paisagem dominada pelas plantações de cana e o atropelamento de animais.

Ao mesmo tempo em que os entrevistados citaram os principais problemas ambientais locais, apenas $21 \%$ deles demonstraram perceber a influência das ações realizadas nos lotes, sobre a reserva. Quando questionados se estariam dispostos a realizar alguma ação em seu lote com o objetivo de proteger melhor a RPPN, a 
maioria dos entrevistados respondeu de modo afirmativo, embora apenas uma parte desses soubesse exemplificar essas ações.

A maioria dos entrevistados afirmou praticar a pesca, principalmente no Rio Paraná. A atividade da pesca acrescenta outros riscos ambientais à reserva, em função de sua localização na foz do Rio Aguapeí, no Rio Paraná. Apesar das restrições legais à realização da pesca no Rio Aguapeí, existem relatos de sua ocorrência. Além dos riscos ambientais de poluição do rio, práticas como utilização de instrumentos de pesca inadequados, desrespeito ao período de reprodução das espécies e ao tamanho mínimo de exemplares capturados, acrescentam riscos de perda de biodiversidade no ecossistema.

Os entrevistados relataram que não costumam coletar animais ou plantas da reserva. Por outro lado, $51 \%$ deles afirmaram utilizar a reserva como caminho para chegar até o rio. Apesar de ser uma área particular, a empresa proprietária da reserva permite a entrada de moradores do reassentamento na reserva, de modo controlado.

A proximidade entre a reserva e o reassentamento favorece a ocorrência de muitos riscos ambientais à biodiversidade da RPPN Foz do Rio Aguapeí. Ao mesmo tempo, pode representar uma oportunidade de proteção para a mesma, desde que a comunidade valorize a reserva e seja informada sobre a forma de colaborar com sua conservação.

É muito importante, portanto, um trabalho de educação ambiental e extensão rural com essa comunidade, discutindo os riscos ambientais para a reserva, associados com a produção agrária. O reassentamento poderia ser entendido como uma importante área tampão, protegendo a reserva, com a utilização de sistemas de produção agroecológica como, por exemplo, os bosques agroflorestais (Pádua \& Sá, 2007).

Por mais que a educação ambiental realizada em uma comunidade, contribua para a conscientização de seus moradores sobre a importância de proteção das unidades de conservação, ela não é suficiente. São também necessários mecanismos 
de ordenamento territorial e instrumentos jurídicos de controle de atividades desenvolvidas nas propriedades localizadas no entorno das áreas protegidas.

Os municípios situados no entorno das unidades de conservação apresentam um papel decisivo para a proteção dessas áreas, decorrente de suas funções de ordenamento territorial. Por meio de instrumentos como o plano diretor, o município poderia definir zonas especiais no entorno das áreas protegidas, com usos do solo mais compatíveis com a conservação da biodiversidade (VITALLI et al, 2009).

No Sistema Nacional de Unidades de Conservação (SNUC) (BRASIL, 2000) está prevista a delimitação de uma zona de amortecimento, no entorno de unidades de conservação de proteção integral. Essa zona de amortecimento deve ser delimitada no zoneamento da Unidade de Conservação, durante a elaboração do seu plano de manejo.

A RPPN Foz do Rio Aguapeí é uma Unidade de Conservação de uso sustentável, não apresentando, portanto, a obrigatoriedade de delimitação de uma zona de amortecimento ao seu redor. O Município de Paulicéia, entretanto, poderia definir o entorno dessa Unidade de Conservação como uma Zona Especial, sujeita a normas específicas de gerenciamento, por ocasião da elaboração de seu plano diretor. Desse modo, as atividades antrópicas realizadas no Reassentamento Rural Fazenda Buritis estariam condicionadas às determinações contidas em seu plano diretor.

\section{CONSIDERAÇÕES FINAIS}

O presente estudo, realizado no Reassentamento Rural Fazenda Buritis, identificou vários riscos ambientais para a integridade da RPPN Foz do Rio Aguapeí, associados com as atividades antrópicas realizadas no local. Alguns desses riscos foram percebidos pelos moradores, que os citaram em suas falas, durante as entrevistas realizadas no reassentamento. Outros, ainda precisam ser conhecidos pela comunidade, mediante a realização de programas educativos, o que em muito poderia contribuir com a proteção dessa unidade de conservação. 
Ao mesmo, é fundamental a ação do poder público, enquanto responsável pelo ordenamento territorial, disciplinando a ocupação antrópica no entorno da RPPN Foz do Rio Aguapeí no âmbito do município.

\section{REFERÊNCIAS}

APOENA (Associação em Defesa do rio Paraná, Afluentes e Mata Ciliar). Unidades de Conservação. http://www.apoena.org.br/corredor-da-biodiversidade-detalhe.php?cod=167. Acesso em 11 de agosto de 2011.

BORDEST, S. M. L. Riscos ambientais na Alta Bacia do Coxipó - MT. UNESP, Rio Claro, 1992. (Tese de Doutorado).

BRASIL. Lei $\mathrm{n}^{\circ}$ 9985, de 18 de junho de 2000. Institui o Sistema Nacional de Unidades de Conservação. 2000.

BRASIL. Resolução CONAMA n 428, de 17 de dezembro de 2010. 2010.

FREITAS LIMA, E. A. C.; SILVA, H. R., \& ALTIMARE, A. L. Uso atual da terra no Município de Ilha Solteira, SP, Brasil: riscos ambientais associados. Holos Environment, V.4, N.2, p.81-96. 2007.

PADUA, S. M. \& SÁ, L. M. B. M. A influência da educação ambiental na região do Pontal do Paranapanema e no Instituto de Pesquisas Ecológicas (Ipê). In: In: JUNQUEIRA, V. \& NEIMAN, Z. (orgs.). Educação Ambiental e conservação da biodiversidade: reflexões e experiências brasileiras. Barueri, Manole. 2007. p.121-137.

PIRES, J. S. R. Análise ambiental voltada ao planejamento e gerenciamento do ambiente rural: abordagem metodológica aplicada ao Município de Luiz Antônio - SP. São Carlos, UFScar, 1995. 194p. (Tese de Doutorado).

PRIMACK, R.B., RODRIGUES, E. Biologia da Conservação. Londrina. Livroceres, 2001, 328p.

TORRES, D. F.; OLIVEIRA, E. S.; ALVES, R.R.N.; VASCONCELLOS, A. Etnobotânica e etnozoologia em unidades de conservação: uso da biodiversidade na APA de Genipabu, Rio Grande do Norte, Brasil. Interciência, v.34, n.9, p.623-629, 2009.

VITALLI, P. L.; ZAKIA, M. J. B. DURIGAN, G. Considerações sobre a legislação correlata à zona tampão de Unidades de Conservação no Brasil. Ambiente e Sociedade, v. 12, n.1, p.87-92, 2009. 